\title{
基于MODIS-EVI评估三江源高寒草地的保护成效
}

\author{
宋瑞玲 ${ }^{1}$ 王 吴 $1^{*}$ 张 迪 ${ }^{1}$ 吕植1,2 朱子云 ${ }^{1,2}$ 张 璐 ${ }^{1}$ \\ 刘炎林 ${ }^{1,3}$ 才文公保 ${ }^{2}$ 吴 岗 ${ }^{1}$ \\ 1 (北京大学生命科学学院自然保护与社会发展研究中心, 北京 100871) \\ 2 (北京山水自然保护中心, 北京 100871) \\ 3 (中国林业科学院森林生态环境与保护研究所, 北京 100091)
}

\begin{abstract}
摘要：三江源是我国生态保护的优先区域。自2005年以来，国家投入大量资金在三江源实施了一系列生态保护措 施和工程, 主要目的之一是保护和恢复草地生态系统。本文基于中分辨率成像光谱仪(MODIS)增强型植被指数 (EVI)数据和野外实测样方, 从草地生物量的角度评估了三江源工程的保护成效, 以期为后续的保护措施提供参 考。本文使用2000-2016年间在青藏高原248个样地的实测地上生物量数据和同期的EVI数据，比较了通过EVI估算 草地地上生物量的不同建模方法, 并从中选择表现最佳的乘幂模型反演了三江源高寒草地的地上生物量, 用趋势 分析法得出了生物量的变化。结果显示, 2000-2016年间, 三江源高寒草地地上生物量没有发生显著变化的面积占 $62 \%$, 显著增加的地方主要在西部和北部, 占 $22 \%$, 显著减少的地方则主要在中部和南部, 占 $16 \% ; 2000-2016$ 年间, 草地地上生物量的年际波动较大，但总趋势不显著; 在2012年后, 地上生物量表现出显著降低的趋势。三江源国家 级自然保护区外部的草地地上生物量高于内部, 使用匹配法比较保护区内外草地地上生物量变化的情况, 结果发 现在生态保护工程实施的2005-2012年间，三江源保护区内的草地生物量没有显著增加。
\end{abstract}

关键词：三江源; 草地退化; 成效评估; 自然保护区; 生物量; MODIS-EVI

\section{Conservation outcomes assessment of Sanjiangyuan alpine grassland with MODIS-EVI approach}

\author{
Ruiling Song ${ }^{1}$, Hao Wang ${ }^{1 *}$, Di Zhang ${ }^{1}$, Zhi Lü ${ }^{1,2}$, Ziyun Zhu ${ }^{1,2}$, Lu Zhang ${ }^{1}$, Yanlin Liu ${ }^{1,3}$, \\ Caiwengongbao ${ }^{2}$, Lan $\mathrm{Wu}^{1}$ \\ 1 Center for Nature and Society, School of Life Sciences, Peking University, Beijing 100871 \\ 2 Shanshui Conservation Center, Beijing 100871 \\ 3 Institute of Forestry Ecology, Environment and Protection, Chinese Academy of Forestry, Beijing 100091
}

\begin{abstract}
The Sanjiangyuan Region is a priority area for ecosystem conservation in China. Since 2005, the government has contributed significant funding to implement ecological conservation and restoration to protect and restore the grasslands. This study correlated aboveground biomass (AGB) data from 248 sites scattered across the Sanjiangyuan Region with MODIS Enhanced Vegetation Index (EVI) data from 2000 to 2016 and utilized four regression models to estimate AGB by EVI. Results showed that power-function model worked best for grasslands in the Sanjiangyuan Region. Trend analysis showed no significant trends in $62 \%$ of the area of Sanjiangyuan, with $22 \%$ of the area, mainly distributed in the western and northern regions, increasing significantly and $16 \%$ of the area, sporadically located in the central and southern regions, decreasing significantly from 2000 to 2016. In general, the AGB of the entire area showed no significant increases or decreases with high annual fluctuations since 2000. However, there have been significant decreases since 2012. The AGB inside of the Sanjiangyuan Nature Reserve was lower than that found outside, and didn't increase significantly during first-stage projects between 2005 and 2012, based on results from matching methods.
\end{abstract}

收稿日期: 2017-07-04; 接受日期: 2018-01-18

* 通讯作者 Author for correspondence. E-mail: wanghao@pku.edu.cn 
Key words: Sanjiangyuan Region; rangelands degradation; effectiveness assessment; nature reserve; biomass; MODIS-EVI

三江源 $\left(89.4^{\circ}-102.2^{\circ} \mathrm{E}, 31.5^{\circ}-36.3^{\circ} \mathrm{N}\right)$ 位于青海 省南部、青藏高原的腹地, 是长江、黄河、澜沧江 的发源地, 被称为“中华水塔”。三江源总面积约 36.3 万 $\mathrm{km}^{2}$, 占青海省总面积的 $50.4 \%$ 。东西跨度约 $1,150 \mathrm{~km}$, 南北跨度约 $490 \mathrm{~km}$, 平均海拔在 $4,000 \mathrm{~m}$ 以上。三江源也是青藏高原生物多样性最集中的地 区(刘敏超等, 2005)和全球气候变化的敏感区(Su et al, 2015), 是我国青藏高原生态安全屏障的重要组 成部分。高寒草地是三江源分布最广泛、最主要的 植被类型, 约占总区域面积的 $65 \%$, 草地以高寒草 甸和高寒草原为主, 分别占 76\%和 23\% (徐新良等, 2008)。高寒草地是三江源生物多样性和生态系统服 务功能、畜牧业生计和文化的基础, 恢复草地生态 是三江源保护工程的主要目标之一。

近几十年来, 由于受到全球气候变暖和人类活 动加剧的双重影响, 该区域生态系统发生了严重退 化(邵全琴和焚江文, 2012)。为保护三江源的生态环 境, 青海省在 2000 年建立了面积为 15.2 万 $\mathrm{km}^{2}$ 的三 江源自然保护区, 2003年保护区升为国家级, 2012 年范围调整后面积变为 14.8 万 $\mathrm{km}^{2}$ 。2005年, 国务院 批准实施《青海三江源自然保护区生态保护和建设 总体规划》(以下简称《一期规划》, 相应的工程称 “一期工程”), 总投资75亿元。建设内容包括生态保 护与建设项目(49.2亿元)、农牧民生产生活设施项目 (22.2亿元)和支撑项目 (3.6亿元)等 3 大类 22 项, 重点 工程区为三江源国家级自然保护区，包括全部18个 自然保护分区，面积占三江源地区总面积的 $42 \%$ 。 为加强三江源的保护力度, 2011年国务院又批准实 施《青海三江源国家生态保护综合试验区总体方 案》, 总投资近 160.6 亿元, 范围扩展为整个综合试 验区, 即包括玉树、果洛、海南、黄南4个州的 21 个县和格尔木市的唐古拉山镇的总面积 39.5 万 $\mathrm{km}^{2}$ 的区域, 规划期限为2013-2020年(邵全琴等, 2016)。

为更有效地实施大规模的生态保护和建设工 程, 中国科学院地理科学与资源研究所牵头多家单 位对一期工程的生态成效进行了监测和综合评估, 基于十几个研究机构和政府相关部门连续多年 (2005-2012)的监测, 结合多种遥感数据的解译及空
间分析，评估了一期工程前后三江源的气候、植被、 土壤、水文等多个方面的变化。评估认为, 重点工 程区内生态恢复程度好于非工程区，除了气候影响 以外，工程的实施对促进植被恢复具有明显而积极 的作用; 然而, 草地退化局面没有获得根本性扭转, 未达到预期的“草地植被盖度平均提高 $20-40 \%$ ”的 目标(邵全琴和㚞江文, 2012; 邵全琴等, 2016)。除 此之外, 相应的保护成效研究还较少。

本研究在对三江源草地实地调查的基础上, 基 于中分辨率成像光谱仪(MODerate-resolution Imaging Spectroradiometer, MODIS)的增强型植被指数 (enhanced vegetation index, EVI) 数据反演生物量, 并进行时间上的趋势分析, 识别出草地生物量明显 增加和减少的区域的空间分布和在工程期间的变 化情况, 以此评估三江源生态保护一期工程对草地 保护的成效; 用匹配法分析了重点工程区一三江 源国家级自然保护区在工程期间对草地地上生物 量变化的作用情况, 并识别出 18 个保护区分区对草 地保护成效的贡献，为提高后续工程的有效性提供 参考。同时在方法上，本研究基于MODIS的植被指 数数据，尝试寻找一种既有说服力，技术和资金门 槛又比较低的方法, 这样既可用于长期监测三江源 的草地变化, 也可以推广应用到类似的评估中。

\section{1 材料与方法}

已有研究表明, 基于遥感影像的植被指数可以 用来评估区域空间尺度的草地质量的变化(Zhao et al, 2005; Zhang et al, 2007; 余晓等, 2011)。本研究使 用的MODIS植被指数数据为MOD13Q1 V005, 空 间分辨率为 $250 \mathrm{~m}$, 时间分辨率为 $16 \mathrm{~d}$ 。与其他卫星 遥感数据相比, MODIS数据的空间分辨率中等, 常 应用于中大尺度的区域评价; 还具有时间分辨率 高、数据免费公开、可以很好地反映植被的时空变 化特征等优势, 在草地遥感监测中的应用越来越广 泛(Eisfelder, 2012; 除多等, 2013)。本研究分析时所 用的EVI综合了MODIS数据集的EVI和PR (像元可 信度, pixel reliability)数据, 去掉了无数据、被冰雪 或云覆盖的数据, 相对更加准确。 
2006-2016年, 本研究组在三江源各地广泛取 样, 累积了 248 个样点(图1)的地上生物量实测数据, 每个样点 3 个重复样方, 总计 744 个样方。为了提高 草地地上生物量遥感反演模型的估算效果, 采样点 的选取考虑了植被分布的特点、地形等因素, 尽量 保证采样数据的代表性和遥感数据的可读性。为了 尽量减小植被指数与样方的空间尺度差异的影响, 尽量选择面积较大、比较均质的草地作为样点。取 样时间为植被生长季盛期7-9月, 以获取当年植被 的最大现存地上生物量。在采样点沿着某一方向设 一条 $150 \mathrm{~m}$ 的样带, 每隔 $50 \mathrm{~m}$ 设一个小样方。样方大 小视植被盖度而定, 盖度在 $50 \%$ 以上的为 $0.5 \mathrm{~m} \times$ $0.5 \mathrm{~m}$, 盖度在 $50 \%$ 以下为 $1 \mathrm{~m} \times 1 \mathrm{~m}$ 。用直接收获法 将样方内植被地上部分齐地面剪下来, 装入信封, 做好标记。实验室内 $85^{\circ} \mathrm{C}$ 烘干至恒重后称量干重。 取每个样点 3 个样方的均值作为该点地上生物量干 重的实测值。

根据每个样点所在地点和取样时间, 从MODIS 数据集中提取该位点对应时相的 EVI值, 分析地上 生物量与EVI的相关关系, 并评估一元线性、二次多 项式、指数、乘幂共 4 种回归模型。用回归方程的 决定系数 $R^{2}$ 表示模型拟合度, 越接近于 1 拟合度越 高; 用地上生物量预测值和实测值之间的误差系数 (公式(1))表示模型的精度, 误差系数越小越好。以 拟合方程的决定系数最大而误差系数最小为最优 评估模型(李聪等, 2007)。

误差系数 $(\%)=($ 预测值 - 实测值 $) /$ 实测值 $\times 100 \%$

依据最优反演模型，用每年生长季6-9月共8个 时相的 $\mathrm{EVI}$ 平均值, 估计每年生长季的平均地上生
物量。叠加中国科学院 1:100万植被类型数据集 (2001), 提取出其中分布最为广泛的高寒草甸和高 寒草原的地上生物量, 作为评估高寒草地质量及变 化的指标。

为评估工程效果, 我们分 3 个时期比较: 2000 2004年为工程前，2005-2012年为工程期，20132016年为工程后。为评估保护区在其中的作用, 我 们基于三江源自然保护区提供的地图数字化了保 护区的边界图层, 分别提取出每年保护区内外及各 个保护分区的高寒草地地上生物量, 比较保护区内 部和外部的异同。该操作在ArcGIS 10.2.1中完成。 对每个时间段, 用一元线性回归的方法分析地上 生物量和EVI的变化趋势(余晓等, 2011; 顾垒等, 2015)。

总体的保护成效是每个空间单元上保护成效 的汇总, 要提高后续工程的成效以达成预期总目标, 可以通过GIS分析识别出负成效所在的区域、驱动 力和相关的管理机构, 从而使得工程的实施更加 科学有效。近年来, 在保护区成效评估中所使用的 匹配法(matching method)可以有效地降低由空间 位置、地理和人为干扰等因素带来的误差, 更准确 地解析出保护区内外生态指标的差别(Joppa \& Pfaff, 2011; 王伟等, 2016; 陈冰等, 2017)。匹配法的应用 出现于20世纪40年代(Greenwood, 1945), 通过构建 平衡的观测数据样本组来分析变量之间的因果关 系, 从而估计待评估变量的处理效应(treatment effect) (Rubin, 1974; 温兴祥和杜在超, 2015)。本研究 将保护区的有无作为待评估的变量, 结合三江源的 自然地理情况, 选取海拔、坡度、草地类型

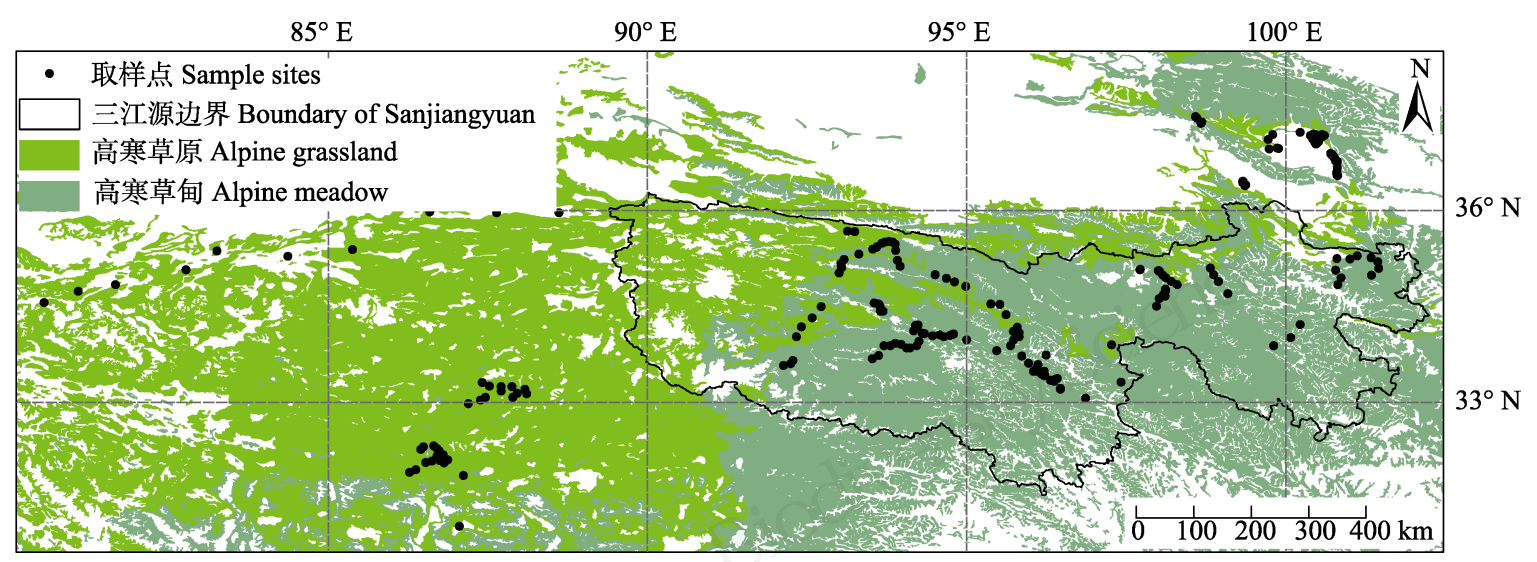

图1 高寒草甸和高寒草原野外实测地上生物量取样点的空间分布

Fig. 1 The locations of the aboveground biomass sample sites of the alpine meadow and alpine grassland 
(高寒草原、高寒草甸)及 2000 年的人口密度 $\left(人 / \mathrm{km}^{2}\right)$ 4个影响因子作为协变量, 以一期工程(2005-2012) 期间三江源草地地上生物量的年均变化率(即一元 回归的系数)作为评估草地保护成效的指标。取样时 对研究区域进行网格化处理, 在保护区内每 $1.5 \mathrm{~km} \times$ $1.5 \mathrm{~km}$ 网格内取中心点(58,657个), 保护区外每 $1 \mathrm{~km} \times 1 \mathrm{~km}$ 网格内取中心点(117,552个), 使得对照 组的样本量多于处理组, 以得到更佳的匹配效果 (Ho et al, 2007; Sekhon, 2011), 将取样点分别与30 $\mathrm{m}$ 分辨率DEM数据、草地类型数据及 $1 \mathrm{~km}^{2}$ 分辨率人 口密度数据叠加, 实现对上述 4 个协变量的信息提 取。选用倾向评分匹配法(propensity score matching) 将协变量转换为介于 $0-1$ 之间的倾向分, 然后从处 理组(保护区内)和对照组(保护区外)中选择倾向分 最为接近的匹配样本, 比较匹配样本间的地上生物 量变化之间的差异(公式(2), Rosenbaum \& Rubin, 1983)。

处理组平均处理效应 $(A T T)=$

$$
E\left(Y_{i 1} \mid T_{i}=1\right)-E\left(Y_{i 0} \mid T_{i}=1\right)
$$

其中，Y为因变量(2005-2012年间地上生物量的年 均变化率), $i$ 为第 $i$ 个样本, $T$ 为处理变量(保护区有无)。

为获得更准确的评估结果, 在对照区域中排除 了青藏公路以西包括可可西里国家级自然保护区 在内的范围, 以及在评估期间可能受到湿地扩张影 响的近湖区域(即基于GLOBAL LAND30土地利用 图, 排除其中的水体和湿地, 及其周边 $1 \mathrm{~km}$ 范围内 且2012年地上生物量 $<10 \mathrm{~g} / \mathrm{m}^{2}$ 的区域)。匹配分析时, 规定参与匹配的协变量标准差不超过 0.2 (caliper $=$ 0.2), 取样与变量获取在ArcGIS 10.2.1中完成, 匹 配及数据分析在R 3.3.1中完成。

\section{2 结果}

\section{1 地上生物量反演模型}

248 个实测样地地上生物量为 $0.85-339.6 \mathrm{~g} / \mathrm{m}^{2}$,
平均76.6 $\pm 70.15 \mathrm{~g} / \mathrm{m}^{2}$ 。其中, 高寒草甸的地上生物 量为 $116.25 \pm 76.02 \mathrm{~g} / \mathrm{m}^{2}$, 高寒草原的地上生物量为 $37.67 \pm 32.16 \mathrm{~g} / \mathrm{m}^{2}$ 。实测地上生物量与对应EVI之间 的Pearson相关系数为 0.779 , 达到了 0.01 水平(双侧) 上的显著相关, 即可以通过EVI来监测植被地上生 物量的变化。

4 种回归模型中(表1), 乘幕函数的决定系数最 大, 而平均误差系数最小, 为其中的最优模型。因 此选择乘幂模型来估算三江源高寒草地地上生物 量。当EVI $<0.3$ 时，估计值误差较小; 而三江源高 寒草地的EVI绝大部分都低于 0.3 , 用该模型能够得 到较准确的地上生物量估计值。

\section{2 地上生物量时空分布格局及保护区内外的比较}

依据乘幕模型，基于每年6-9月共8个时相的 EVI平均值估计得到每年生长季的高寒草地平均地 上生物量。2016年三江源草地地上生物量总体上呈 现从东南到西北逐渐减少的梯度分布。最高的在东 部河南、泽库等县, 平均 $140 \mathrm{~g} / \mathrm{m}^{2}$; 最低的在西北部 可可西里, 约 $20 \mathrm{~g} / \mathrm{m}^{2}$; 三江源高寒草地总体平均是 $60 \mathrm{~g} / \mathrm{m}^{2}$ 。

2000-2016年, 保护区内草地地上生物量平均 为 $61.9 \mathrm{~g} / \mathrm{m}^{2}$, 保护区外为 $63.2 \mathrm{~g} / \mathrm{m}^{2}$ 。每年保护区内 的草地地上生物量都低于保护区外，二者的总体年 际波动变化一致。总体来看, 2000-2016年保护区内 外的地上生物量的变化斜率都小于零，但趋势并不 显著(图2)。以三江源一期工程的起止年为节点, 在 工程实施期间(2006-2012), 保护区内外的草地地上 生物量都显著高于工程实施之后(2013-2016) (保护 区内 $P=0.013$, 保护区外 $P=0.023)$, 而与工程实施 之前的没有显著性差异。

2000-2016年，像素水平上EVI的趋势分析结 果表明，三江源高寒草地地上生物量没有发生显著 变化的面积占 $62 \%$ ，显著增加的面积占 $22 \%$ ，显著 减少的面积占 $16 \%$ 。无论保护区内外, $60 \%$ 以上草地

表1 据实测地上生物量与对应增强型植被指数 $(\mathrm{EVI})$ 建立的4种回归模型(其中 $X$ 为 EVI, $Y$ 为地上生物量)

Table 1 The four regression models based on the measured aboveground biomass and the related enhanced vegetation index (EVI) ( $X=\mathrm{EVI} ; Y=$ aboveground biomass $)$

\begin{tabular}{lllll}
\hline 模型 Model & 拟合方程 Function & 决定系数 $R^{2}$ Coefficients of determination & Sig. & $\begin{array}{l}\text { 平均误差系数 Mean error coeffi- } \\
\text { cients }\end{array}$ \\
\hline 线性 Linear & $Y=376.571 X-17.075$ & 0.606 & $<0.001$ & $33.4 \%$ \\
二次 Quadratic & $Y=163.385 X^{2}+280.199 X-6.634$ & 0.609 & $<0.001$ & $43.0 \%$ \\
乘幂 Power & $Y=383.897 X^{1.3}$ & 0.675 & $<0.001$ & $24.3 \%$ \\
指数 Exponential & $Y=11.977 \mathrm{e}^{5.653 X}$ & 0.611 & $<0.001$ & $32.4 \%$ \\
\hline
\end{tabular}




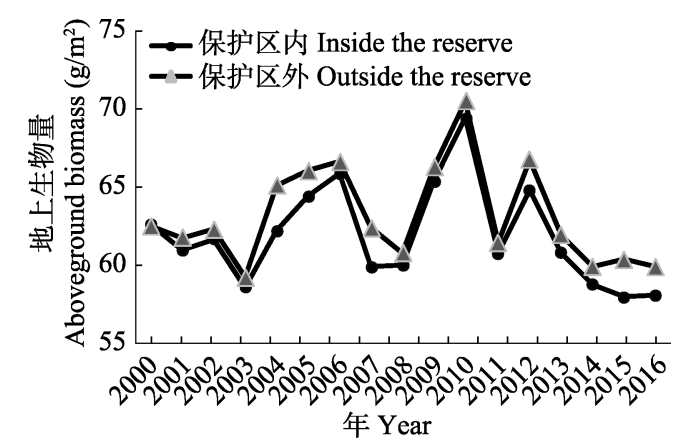

图2 2000-2016年三江源自然保护区内外生长季平均地上 生物量的波动变化

Fig. 2 The fluctuations of the average aboveground biomass of the growing season inside and outside of Sanjiangyuan Nature Reserve (2000-2016)

面积的EVI都没有显著变化(图3)。相比而言, 保护 区内EVI显著减少的面积比例为 $17.3 \%$, 大于保护 区外 $(14.6 \%)$; 而保护区内EVI显著增加的面积比例 为 $19.6 \%$, 小于保护区外 $(23.8 \%)$ 。综合上述结果, 保 护区外的草地地上生物量相对更高, 草地生物量增 加的面积也更多一些。

\section{3 草地生物量发生明显变化的区域}

由图3可知, EVI显著增加的区域主要在三江源 的北部和西部, 如可可西里保护区、玛多县、兴海 县、同德县和泽库县的北部; EVI显著减少的区域主 要在三江源中部和南部, 如玉树州的囊谦县、杂多 县、称多县、曲麻莱和治多的东部, 以及果洛州的 久治县、甘德县, 特别是甘德与达日交界的地方。

各保护分区的变化情况各不相同。位于三江源 北部的星星海、约古宗列、麦秀保护区, EVI显著增
加的面积比例较高, 在 $25 \%$ 以上, EVI显著降低的比 例不到 $10 \%$; 相反，位于南部的保护分区，如江西、 果宗木查保护区, EVI显著降低的比例较高, 约 $30 \%$ 。同时, 本研究注意到, 青藏公路以西没有实施 工程的区域, EVI显著增加的比例较大, 如可可西里 自然保护区，2000-2016年间地上生物量显著增加， EVI显著增加的比例达 $40 \%$ 。

\section{4 保护区成效的匹配法分析结果}

将一期工程(2005-2012)期间三江源草地地上 生物量的年均变化率(即一元回归的系数)作为评估 草地保护成效的指标, 分别评估青藏公路以东三江 源保护区、18个保护分区及核心区的保护成效。运 用倾向评分匹配后，海拔、坡度、草地类型、人口 密度这 4 个协变量在保护区内外的差距都缩小(表2), 草地类型趋于一致(以高寒草甸为主，含部分高寒 草原)。在此基础上的分析结果表明, 实施一期工程 后三江源保护区内草地地上生物量变化的平均处 理效应(ATT)为 -158.170 (表3), 差异性检验 $P$ 值为 0.000 。

在紧邻保护区的区域内，可能存在保护区的 “溢出效应(neighborhood leakage)” (Andam et al, 2008), 即保护区建立对周边自然资源可能产生的 或正面或负面的额外影响, 多发生在 $10 \mathrm{~km}$ 范围内 (Clements et al, 2014; 陈冰等, 2017)。若将保护区外 $10 \mathrm{~km}$ 缓冲带内样本去除以减少溢出效应, 重复上 述分析, 得到 $A T T=-126.700$ (表3), 差异性检验 $P=$ 0.002; 依据断点回归的设计思路, 将保护边界内外

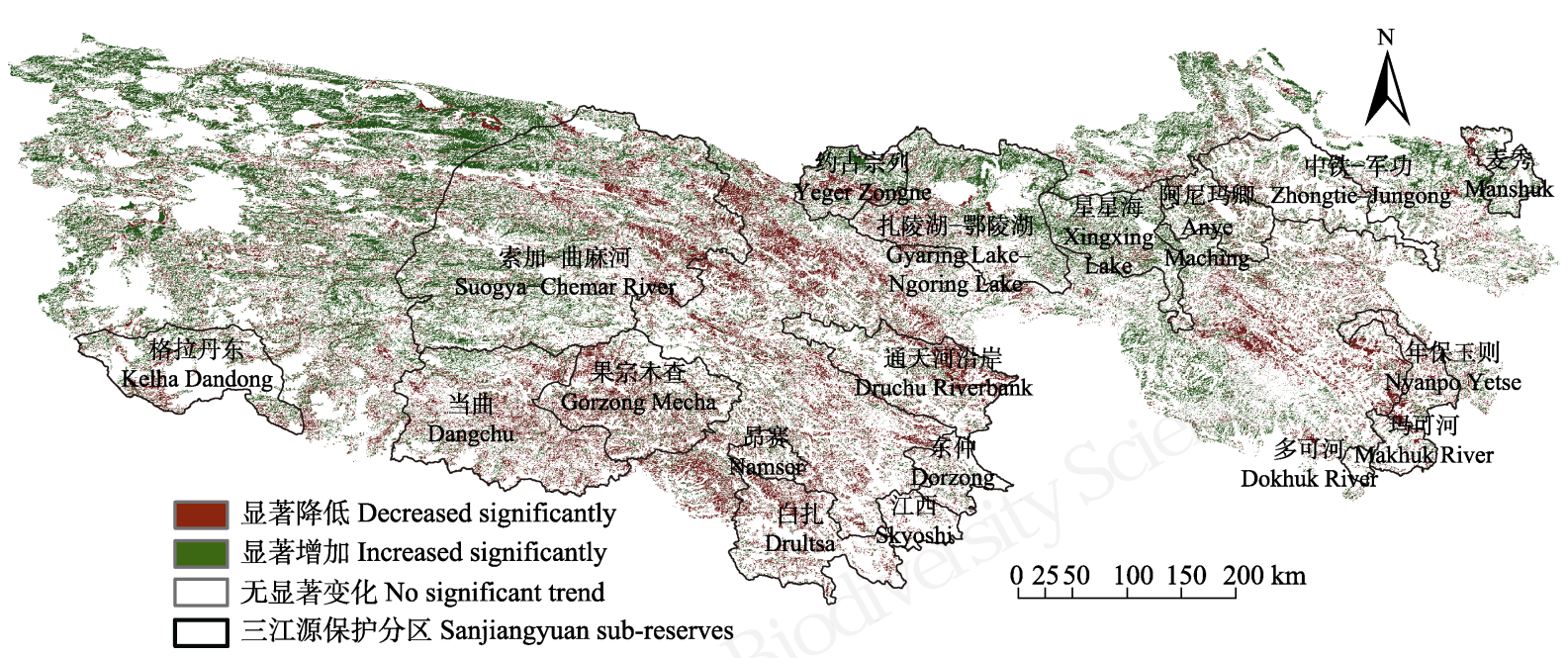

图32000-2016年三江源高寒草地生长季平均增强型植被指数(EVI)变化的空间分布

Fig. 3 The spatial pattern of the trend of average enhanced vegetation index (EVI) of the growing season from 2000 to 2016 in Sanjiangyuan Region 
各5 $\mathrm{km}$ 范围内的样点进行匹配分析, 结果得 $A T T=$ $-211.200, P=0.000$ (表3)。两种分析结果与之前不 考虑“溢出效应”的分析结果一致, 表明一期工程实 施期间(2005-2012年), 三江源保护区内草地地上生 物量的年均增长率较保护区外更低。

对18个保护分区单独进行分析, 保护区内草 地地上生物量年均增长率高于保护区外 $(A T T>0$ 且 差异性显著)的有果宗木查、索加-曲麻河、玛可 河、年保玉则和通天河沿岸共 5 个保护分区(表 4 , 图 4), 其余保护分区则无明显差异或增长率更低(表4, 图4)。

\section{3 讨论}

本文通过2000-2016年的MODIS-EVI数据和实 测地上生物量数据, 建立了估计三江源高寒草地地 上生物量的模型。由于样方大小与EVI像元大小之 间有较大差异, 反演结果有一定的不确定性, 本文 并未将反演结果作为输入变量用于进一步的计算, 同时也未去推算对误差有精细要求的问题。本文着 重分析了区域尺度上地上生物量的空间分布格局 和时间变化趋势。在空间分布上, 地上生物量总体 呈现从东南到西北逐渐减少的梯度分布, 这与已有 研究结果一致(Fan et al, 2010; 孙庆龄等, 2016), 与
西高东低的地势, 以及西北干冷东南温润的温度和 湿度的梯度吻合。在时间序列上，这种纵向比较大 大降低了反演所带来的不确定性, 可以用于对地上 生物量变化趋势的判断和比较。基于MODIS-EVI 的评估方法在技术和资金方面的门槛较低，可用于 持续监测和快速评估区域尺度上草地的变化。

对草地生物量变化趋势的分析结果表明, 20002016年三江源地上生物量总体有所减少，但变化趋 势并不显著。肖桐等(2014)基于MODIS-NDVI的评 估认为, 2000-2011年三江源草地覆盖度总体增加, 特别是黄河源区域; 张继平等(2015)的评估结果表 明, 2000-2010年, 三江源草地净初级生产力在波动 中有所增加。邵全琴等(2016)和孙庆龄等(2016)的结 果也都认为三江源草地覆盖度在2000-2013年总体 呈增加趋势。这些研究中选择的评估时段不同，回 归得到的地上生物量或植被指数等指标的年变化 率会有所不同, 但从其数据的波动情况看, 均没有 显著变化趋势。其中三江源北部和西部有较多区域 的地上生物量显著增加, 而中部和东部则有较多区 域的地上生物量显著减少，地上生物量的增加很可 能主要受气候暖湿化的影响(Lehnert et al, 2016; 邵 全琴等, 2016)。气候数据表明, 近十几年来, 三江源 气候持续变暖(Fan et al, 2010; 邵全琴等, 2016), 北

表2 匹配后处理组(三江源保护区内)与对照组(保护区外)在4种协变量上的差距缩小

Table 2 The differences of the 4 covariates inside and outside of Sanjiangyuan Nature Reserve were smaller after matching

\begin{tabular}{|c|c|c|c|c|c|}
\hline $\begin{array}{l}\text { 匹配前后 } \\
\text { Before \& after } \\
\text { matching (BM \& AM) }\end{array}$ & $\begin{array}{l}\text { 统计值 } \\
\text { Statistics }\end{array}$ & $\begin{array}{l}\text { 海拔 } \\
\text { Elevation (m) }\end{array}$ & $\begin{array}{l}\text { 坡度 } \\
\text { Slope }\left(^{\circ}\right)\end{array}$ & $\begin{array}{l}\text { 草地类型(高寒草甸/高寒草原) } \\
\text { Grassland type (Alpine meaw/ } \\
\text { Alpine steppe) }\end{array}$ & $\begin{array}{l}\text { 人口密度 }\left(\text { 人 } / \mathrm{km}^{2}\right) \\
\text { Population } \\
\text { density }(\text { per km²) }\end{array}$ \\
\hline 匹配前 BM & $\begin{array}{l}\text { 均值 Mean } \\
\text { (内/外 Inside/Outside) }\end{array}$ & $\begin{array}{l}4,567.200 \\
/ 4,414.500\end{array}$ & $10.911 / 12.770$ & $1.129 / 1.092$ & $0.799 / 2.782$ \\
\hline 匹配后 AM & $\begin{array}{l}\text { 均值 Mean } \\
\text { (内/外 Inside/Outside) }\end{array}$ & $\begin{array}{l}4,566.700 \\
/ 4,572.500\end{array}$ & $10.914 / 11.085$ & $1.129 / 1.120$ & $0.799 / 1.752$ \\
\hline 匹配前 BM & $\begin{array}{l}\text { 标准化均数差 } \\
\text { Standardized mean difference }\end{array}$ & 49.409 & -19.899 & 11.040 & -9.659 \\
\hline 匹配后 AM & $\begin{array}{l}\text { 标准化均数差 } \\
\text { Standardized mean difference }\end{array}$ & -1.894 & -1.833 & 2.453 & -4.639 \\
\hline
\end{tabular}

表3 三江源保护区内外地上生物量年均变化率的处理组平均处理效应(ATT)和配对 $t$ 检验结果

Table 3 Results of the average treatment effect on the treated (ATT) and paired-samples $t$-test of aboveground biomass change rate inside and outside of Sanjiangyuan Nature Reserve (NR)

\begin{tabular}{lllll}
\hline 序号 No. & 评估对象(处理组/对照组) Items（treatment/control） & $A T T$ & $t$ & $P$-value \\
\hline 1 & 保护区内/外 Inside/outside of NR & -158.170 & -4.7394 & $0.000^{* *}$ \\
2 & 保护区内/外(去除10 km 缓冲区) Inside/outside (without 10 km buffer) of NR & -126.700 & -3.030 & $0.002^{* *}$ \\
3 & 保护区内/外 $5 \mathrm{~km}$ 缓冲区 $5 \mathrm{~km}$ buffer inside and outside the border of NR & -211.200 & -5.755 & $0.000^{* *}$ \\
4 & 保护区核心区 Core areas of NR & -185.410 & -5.668 & $0.000^{* *}$ \\
\hline
\end{tabular}

**P<0.01. 
表4 18 个保护分区的草地地上生物量年均变化率的处理组平均处理效应(ATT)和配对 $t$ 检验结果

Table 4 Results of the average treatment effect on the treated (ATT) of aboveground biomass change rate inside and outside of 18 sub-reserves

\begin{tabular}{lllll}
\hline 序号 No. & 保护分区 Sub-reserves & $A T T$ & $t$ & $P$-value \\
\hline 1 & 格拉丹东 Kelha Dandong & -119.880 & -0.777 & 0.436 \\
2 & 麦秀 Manshuk & -139.200 & -0.770 & 0.442 \\
3 & 果宗木查 Gorzong Mecha & 295.070 & 8.240 & $0.000^{* *}$ \\
4 & 当曲 Dangchu & -259.300 & -9.970 & $0.000^{* *}$ \\
5 & 索加-曲麻河 Suogya-Chemar River & 94.364 & 3.438 & $0.001^{* *}$ \\
6 & 多可河 Dokhuk River & -198.440 & -0.600 & 0.548 \\
7 & 玛可河 Makhuk River & 587.030 & 3.740 & $0.000^{* *}$ \\
8 & 年保玉则 Nyanpo Yetse & 540.270 & 5.380 & $0.000^{* *}$ \\
9 & 约古宗列 Yeger Zongne & -309.160 & -7.644 & $0.000^{* *}$ \\
10 & 扎陵湖-鄂陵湖 Gyaring Lake-Ngoring Lake & -777.280 & -19.414 & $0.000^{* *}$ \\
11 & 星星海 Xingxing Lake & -1695.200 & -29.040 & $0.000^{* *}$ \\
12 & 阿尼玛卿 Anye Maching & -584.970 & -8.290 & $0.000^{* *}$ \\
13 & 中铁-军功 Zhongtie-Jungong & -612.480 & -7.840 & $0.000^{* *}$ \\
14 & 通天河沿岸 Druchu Riverbank & 609.100 & 8.250 & $0.000^{* *}$ \\
15 & 东仲 Dorzong & -568.930 & -4.140 & $0.000^{* *}$ \\
16 & 江西 Skyoshi & -966.400 & -5.270 & $0.000^{* *}$ \\
17 & 白扎 Drultsa & -285.800 & -4.670 & $0.000^{* *}$ \\
18 & 昂赛 Namser & -755.750 & -5.510 & $0.000^{* * *}$ \\
\hline
\end{tabular}

**P<0.01.

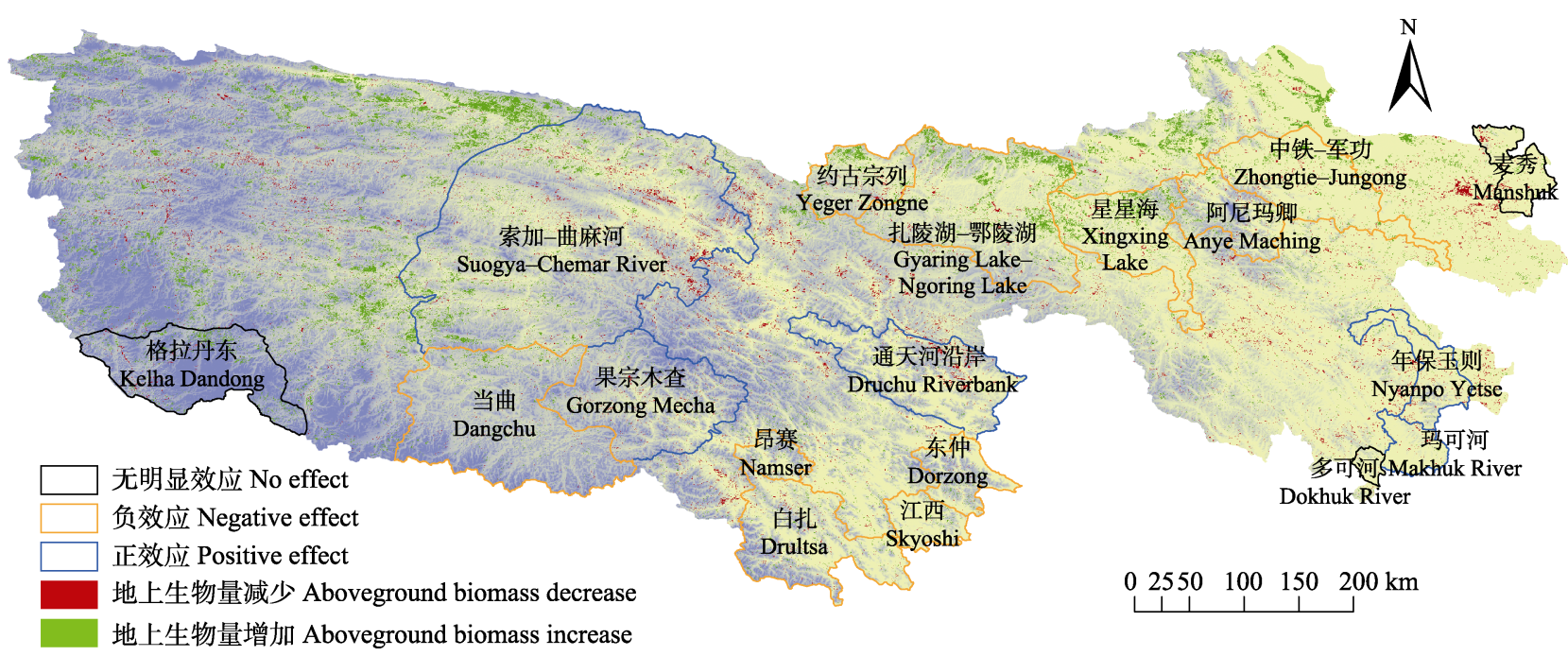

图4一期工程期间(2005-2012)三江源生长季平均地上生物量变化的空间分布及各保护分区成效示意图

Fig. 4 The spatial pattern of the trend of average biomass of growing season during the first-stage projects period (2005-2012) in Sanjiangyuan and the protection effectiveness in each sub-reserve

部和西部的降水有所增加(王军邦等, 2009; Long et al, 2010; Lehnert et al, 2016; 孙庆龄等, 2016), 植被 指数的增加与气温和降水有更高的正相关性(孙庆 龄等, 2016)。而三江源草地生物量显著增加的西部 和北部区域大部分是在工程区(保护区)外, 保护区
内的草地变化并不显著(图3)。

使用倾向评分匹配法降低地形、人口等变量可 能带来的评估偏差后，保护区内的草地地上生物量 与保护区外相比并未显示更为积极的变化，区内的 平均处理效应为负值, 显示保护区内草地变好的程 
度较保护区外更低。推测可能的情况包括：在生物 量变化速度上, 区内比区外的地上生物量降低速度 更快, 或增加速度更慢; 在生物量变化的面积上, 区内生物量减少的区域面积更大, 或生物量增加的 区域面积更小。保护区未显示出正效应, 也可能与 保护工程的实施未严格参照保护区边界执行有关, 工程中资金占比最大的项目，如退牧还草工程(42\%) 等都是以行政单元(乡镇)来执行的; 实地考察时, 在有保护区的行政单元中, 也并未发现保护行动力 度有区内和区外的差异。

本研究以从MODIS-EVI估算出的生物量增加 作为保护有成效的指标, 评估方法快捷, 能够说明 一定的问题。然而仅凭生物量增加这一个指标, 或 不足以说明草地质量和生物多样性的改善, 灌木入 侵、缺乏饲用价值的植物增加、退化指示种大量繁 殖等都会导致生物量增加但草地质量下降的情况, 因此需要进一步增加物种组成、群落结构分析等 内容。

本文结果与邵全琴等(2016)对三江源保护一期 工程的评估所得出的草地生物量的分布及其变化 格局基本一致, 即草地生物量减少的趋势并未发生 逆转, 但与其认为“生态保护工程对草地生物量的 增加起了正面作用”的结论不尽相同, 本研究未发 现保护区内因工程实施而显示出正面效应。此外, 有研究认为保护工程中的部分措施如围栏封育、毒 杀鼠兔等对恢复退化草地和保护生物多样性没有 积极作用(Harris, 2010; Wu \& Wang, 2017)。三江源 地区生态环境严酷、植被脆弱, 对气候变化非常敏 感。为遏制草地退化和增强应对气候变化的抵抗力, 一方面需要进一步增加保护关注和投资力度, 另一 方面则需要提高保护行动之间的协调和措施的成 效。建议针对目前正在实施的《青海三江源国家生 态保护综合试验区总体方案》, 进行更细致的成效 评估, 并基于评估结果重新审阅工程中有争议的保 护行动, 以实现保护三江源的初衰。

致谢: 本研究在研究思路上和野外调查中得到了 George Beals Schaller 博士、顾垒博士和山水自然保 护中心的工作人员和十几位研修生的帮助; 使用的 MODIS-EVI 数据来自美国大地调查局(USGS)地球 资源观察和科学中心(EROS) 的陆地科学研究小组 (LPDAAC), 特此致谢。

\section{参考文献}

Andam KS, Ferraro PJ, Pfaff A, Sanchez-Azofeifa GA, Robalino JA (2008) Measuring the effectiveness of protected area networks in reducing deforestation. Proceedings of the National Academy of Sciences, USA, 105, 16089-16094.

Chen B, Liu FZ, Zhang YB, Du JH, Wang W, Li JS (2017) Assessment of forest conservation in the Cangshan Nature Reserve based on propensity score matching. Biodiversity Science, 25, 999-1007. (in Chinese with English abstract) [陈冰，刘方正，张玉波，杜金鸿，王伟，李俊生 (2017) 基于倾向评分配比法评估苍山自然保护区的森林保护成 效. 生物多样性, 25, 999-1007.]

Chu D, Deji YZ, Ji QM, Tang H (2013) Aboveground biomass estimate methods for typical grassland types in the Tibetan Plateau. Remote Sensing for Land and Resources, 25(3), 43-50. (in Chinese with English abstract) [除多, 德吉央宗, 姬秋梅, 唐红 (2013) 西藏高原典型草地地上生物量遥 感估算. 国土资源遥感, 25(3), 43-50.]

Clements T, Suon S, Wilkie DS, Milner-Gulland EJ (2014) Impacts of protected areas on local livelihoods in Cambodia. World Development, 64, S125-S134.

Eisfelder C, Kuenzer C, Dech S (2012) Derivation of biomass information for semi-arid areas using remote-sensing data. International Journal of Remote Sensing, 33, 2937-2984.

Fan JW, Shao QQ, Liu JY, Wang JB, Harris W, Chen ZQ, Zhong HP, Xu XL, Liu RG (2010) Assessment of effects of climate change and grazing activity on grassland yield in the Three Rivers Headwaters Region of Qinghai-Tibet Plateau, China. Environmental Monitoring and Assessment, 170, 571-584.

Gu L, Wen C, Luo M, Wang H, Lü Z (2015) A rapid approach for assessing the conservation effectiveness of the most concerned endangered species in China. Biodiversity Science, 23, 583-590. (in Chinese with English abstract) [顾垒, 闻丞, 罗玫, 王吴, 吕植 (2015) 中国最受关注濒危物种 保护现状快速评价的新方法探讨. 生物多样性, 23 , 583-590.]

Greenwood E (1945) Experimental Sociology: A Study in Method. King's Crown Press, New York.

Harris RB (2010) Rangeland degradation on the QinghaiTibetan Plateau: A review of the evidence of its magnitude and causes. Journal of Arid Environments, 74, 1-12.

Ho DE, Imai K, King G, Stuart EA (2007) Matching as nonparametric preprocessing for reducing model dependence in parametric causal inference. Political analysis, 15, 199-236.

Joppa LN, Pfaff A (2011) Global protected area impacts. Proceedings of the Royal Society B: Biological Sciences, 278, 1633-1638.

Lehnert LW, Wesche K, Trachte K, Reudenbach C, Bendix J (2016) Climate variability rather than overstocking causes recent large scale cover changes of Tibetan pastures. Scientific Reports, 6, 24367.

Li C, Xiao JD, Cao ZZ, Shi Y, Yang ZH (2007) Application of MODIS data in remote sensing estimation of prairie biomass in different seasons. Arid Zone Research, 24, 386-391. (in 
Chinese with English abstract) [李聪, 肖继东, 曹占洲, 石 玉，杨志华 (2007) 应用MODIS数据估算草地生物量. 干 旱区研究, 24, 386-391.]

Liu MC, Li DQ, Wen YM (2005) The protection of biological diversity in the Sanjiangyuan Nature Reserve. JournaI of Arid Land Resources and Environment, 19(4), 49-53. (in Chinese with English abstract) [刘敏超, 李迪强, 温琰茂 (2005) 论三江源自然保护区生物多样性保护. 干旱区资 源与环境, 19(4), 49-53.]

Long Y, Zhou L, Liu W, Zhou HK (2010) Using remote sensing and GIS technologies to estimate grass yield and livestock carrying capacity of alpine grasslands in Golog Prefecture, China. Pedosphere, 20, 342-351.

Rubin DB (1974) Estimating causal effects of treatment in randomized and nonrandomized studies. Journal of Educational Psychology, 66, 688-701.

Rosenbaum PR, Rubin DB (1983) The central role of the propensity score in observational studies for causal effects. Biometrika, 70, 41-55.

Sekhon JS (2011) Multivariate and propensity score matching software with automated balance optimization: The matching package for R. Journal of Statistical Software, 42(7), 52.

Shao QQ, Fan JW (2012) Integrated Monitoring and Assessment of Ecosystem in Sanjiangyuan Region. Science Press, Beijing. (in Chinese) [邵全琴，㚞江文 (2012) 三江源区生 态系统综合监测与评估. 科学出版社, 北京.]

Shao QQ, Fan JW, Liu JY, Huang L, Cao W, Xu XL, Ge JS, Wu D, Li ZQ, Gong GL, Nie XM, He T, Wang LY, Bing LF, Li QJ, Chen ZQ, Zhang GQ, Zhang LX, Yang YS, Yang F, Zhou WF, Liu LL, Qi YG, Zhao GS, Li YZ (2016) Assessment on the effects of the first-stage ecological conservation and restoration project in Sanjiangyuan Region. Acta Geographica Sinica, 71, 3-20. (in Chinese with English abstract) [邵全琴, 樊江文, 刘纪远, 黄麟, 曹巍, 徐新良, 葛劲松, 吴丹, 李志强, 巩国丽, 聂学敏, 贺添, 王立亚, 邴龙飞, 李其江, 陈卓奇, 张更权, 张良侠, 杨永顺, 杨 帆, 周万福, 刘璐璐, 祁永刚, 赵国松, 李愈哲 (2016) 三江源生态保护和建设一期工程生态成效评估. 地理学 报, 71, 3-20.]

Su J, Aryal A, Nan Z, Ji W (2015) Climate change-induced range expansion of a subterranean rodent: Implications for rangeland management in Qinghai-Tibetan Plateau. PLoS ONE, 10, e0138969.

Sun QL, Li BL, Xu LL, Zhang T, Ge JS, Li F (2016) Analysis of NDVI change trend and its impact factors in the Three-River Headwater Region from 2000 to 2013. Journal of Geoinformation Science, 18, 1707-1716. (in Chinese with English abstract) [孙庆龄, 李宝林, 许丽丽, 张涛, 葛 劲松, 李飞 (2016) 2000-2013年三江源植被NDVI变化趋 势及影响因素分析. 地球信息科学学报, 18, 1707-1716.]

Wang W, Xin LJ, Du JH, Chen B, Liu FZ, Zhang LB, Li JS (2016) Evaluating conservation effectiveness of protected areas: Advances and new perspectives. Biodiversity Science, 24, 1177-1188. (in Chinese with English abstract) [王伟, 辛利娟，杜金鸿，陈冰，刘方正，张立博，李俊生 (2016) 自然保护地保护成效评估：进展与展望. 生物多样性, 24 , 1177-1188.]
Wang JB, Liu JY, Shao QQ, Liu RG, Fan JW, Chen ZQ (2009) Spatial-temporal patterns of net primary productivity for 1988-2004 based on GLOPEM-CEVSA model in the "Three-River Headwaters" Region of Qinghai Province, China. Chinese Journal of Plant Ecology, 33, 254-269. (in Chinese with English abstract) [王军邦, 刘纪远, 邵全琴, 刘荣高, 㚞江文, 陈卓奇 (2009) 基于遥感-过程耦合模 型的1988-2004年青海三江源区净初级生产力模拟. 植物 生态学报, 33, 254-269.]

Wen XX, Du ZC (2015) Survey on matching method: Theory and applications. Statistical Research, 32(4), 104-112. (in Chinese with English abstract) [温兴祥, 杜在超 (2015) 匹 配法综述: 方法与应用. 统计研究, 32(4), 104-112.]

Wu L, Wang H (2017) Poisoning the pika: Must protection of grasslands be at the expense of biodiversity? Science China Life Science, 60, 545-547.

Xiao T, Wang CZ, Feng M, Qu R, Zhai J (2014) Dynamic characteristic of vegetation coverage in the Three-River Source Region from 2000 to 2011. Acta Agrestia Sinica, 22(1), 39-45. (in Chinese with English abstract) [肖桐, 王 昌佐, 冯敏, 屈冉, 翟俊 (2014) 2000-2011年青海三江源 地区草地覆盖度的动态变化特征. 草地学报, 22(1), 39-45.]

Xu XL, Liu JY, Shao QQ, Fan JW (2008) The dynamic changes of ecosystem spatial pattern and structure in the Three-River Headwaters region in Qinghai Province during recent 30 years. Geographical Research, 27, 829-838, 974. (in Chinese with English abstract) [徐新良, 刘纪远, 邵全 琴, 秲江文 (2008) 30年来青海三江源生态系统格局和空 间结构动态变化. 地理研究, 27, 829-838, 974.]

Yu X, Wang H, Li C, Wang YC (2011) Assessment of vegetation cover change in the Argun basin based on MODIS/EVI. Journal of China Institute of Water Resources and Hydropower Research, 9(2), 110-115. (in Chinese with English abstract) [余晓, 王吴，李棚，王义成 (2011) 基于 MODIS/EVI的额尔古纳河流域植被变化分析. 中国水利 水电科学研究院学报, 9(2), 110-115.]

Zhang JP, Liu CL, Hao HG, Sun L, Qiao Q, Wang H, Ning YC (2015) Spatial-temporal change of carbon storage and carbon sink of grassland ecosystem in the Three-River Headwaters Region based on MODIS GPP/NPP data. Ecology and Environmental Sciences, 24, 8-13. (in Chinese with English abstract) [张继平, 刘春兰, 郝海广, 孙莉, 乔青, 王辉, 宁杨翠 (2015) 基于 MODIS GPP/NPP 数据的三 江源地区草地生态系统碳储量及碳汇量时空变化研究. 生态环境学报, 24, 8-13.]

Zhang L, Wylie B, Loveland T, Fosnight E, Tieszen LL, Ji L, Gilmanov T (2007) Evaluation and comparison of gross primary production estimates for the Northern Great Plains Grasslands. Remote Sensing of Environment, 106, 173-189.

Zhao M, Heinsch FA, Nemani RR, Running SW (2005) Improvements of the MODIS terrestrial gross and net primary production global data set. Remote Sensing of Environment, 95, 164-176.

(责任编委：白永飞 责任编辑：黄祥忠) 